\title{
AVALIAÇÃO DA INGESTÃO DE FRUTAS, VERDURAS E LEGUMES EM IDOSOS RESIDENTES EM CIDADES DA REGIÃO DE CAMPINAS-SP
}

\author{
Bruna Zeferino Mathias*, Beatriz P.S; Gabriela B; Graziele M.S; Carolina N.F; Larissa M.H; Ligiana P.C.
}

\begin{abstract}
Resumo
Objetivo: Avaliar o consumo de frutas, verduras e legumes (FVL) em idosos residentes no município de Limeira e seus fatores associados. Métodos: Foram coletados dados de 159 idosos ( $>60$ anos) e questionadas questões pessoais, socioeconômicas e de saúde. O consumo de FVL foi avaliado por meio de um recordatório de 24 horas e foram considerados com consumo adequado a ingestão $\geq 3$ porções de frutas e $\geq 3$ porções de verduras e legumes. Foram mensuradas prevalências e as diferenças das variáveis pelo teste qui-quadrado $(x 2)$ de Pearson e teste de Mann Whitney com valor crítico de $p<0,05$. A prevalência da adequação do consumo de $F V L$ pelos idosos se mostrou baixa e o consumo inadequado foi associado ao maior IMC e a um menor número de lanches entre as refeições principais ao longo do dia.
\end{abstract}

Palavras-chave: idoso, nutrição, consumo alimentar.

\section{Introdução}

A partir da transição demográfica houve um aumento da expectativa de vida acarretando a um envelhecimento da população'. Nesse contexto, esse processo leva a algumas alterações fisiológicas importantes que podem prejudicar o consumo de frutas, verduras e legumes (FVL) em idosos². Esses alimentos são excelentes fontes de vitaminas, minerais, fibras e fatores antioxidantes, além de prevenirem à ocorrência de doenças crônicas não transmissíveis, muito prevalentes na população idosa.O objetivo do estudo foi avaliar o consumo de frutas, verduras e legumes em idosos residentes no município de Limeira e seus fatores associados.

\section{Resultados e Discussão}

Foram coletados dados de 159 idosos (>60 anos) e questionadas questões pessoais, socioeconômicas e de saúde. $\mathrm{O}$ consumo de FVL foi avaliado por meio de um recordatório de 24 horas e foram considerados com consumo adequado aqueles que apresentaram ingestão $\geq 3$ porções de frutas e $\geq 3$ porções de verduras e legumes, de acordo com o Guia Alimentar para a População Brasileira. Foram mensuradas prevalências e as diferenças das variáveis pelo teste qui-quadrado $\left(X^{2}\right)$ de Pearson e teste de Mann Whitney com valor crítico de $\mathrm{p}<0,05$. A prevalência da adequação do consumo de $\mathrm{FVL}$ pelos idosos se mostrou baixa, somente $38,4 \%$ relataram consumir 3 porções de frutas e 3 porções de verduras e legumes por dia (figura 1).

$\mathrm{O}$ consumo inadequado de FVL se mostrou associado com a menor quantidade de lanches entre as refeições realizadas ao longo do dia (0 à 2), em relação à aqueles que consumiram 3 lanches ou mais $(p<0,01)$. Além disso, esse consumo inadequado se mostrou associado com o maior IMC da população $(p=0,04)$, os resultados estão ilustrados na tabela 1.

No Brasil, o Ministério da Saúde recomenda a realização de 3 refeições diárias principais intercaladas por pelo menos 2 lanches saudáveis por $\mathrm{dia}^{3}$, dado que o maior fracionamento da dieta pelos idosos está relacionado ao auxílio no controle da concentração sérica de glicose, colesterol e na manutenção do peso corporal adequado. Além de disso, esses alimentos possuem baixa densidade energética favorecendo a manutenção do peso de forma saudável.

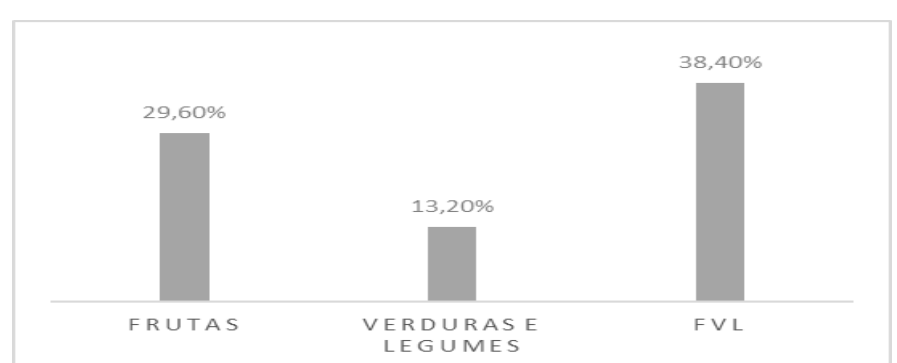

Figura 1. Prevalência da adequação do consumo de FVL dos idosos residentes do município de Limeira-SP.

Tabela 1. Diferenças do consumo de FVL segundo o IMC dos idosos residentes do município de Limeira-SP.

\begin{tabular}{|lccc|}
\hline $\begin{array}{l}\text { Porções de } \\
\text { FVL }\end{array}$ & IMC médio & IC (95\%) & Valor $\mathbf{p}$ \\
Adequado & 27,93 & $26,73-29,12$ & - \\
Inadequado & 29,97 & $28,79-31,15$ & 0,04 \\
\hline
\end{tabular}

Nota: Test U Mann-Whitney

\section{Conclusões}

O baixo consumo de FVL se mostrou prevalente na população sendo associado ao menor consumo de lanches entre as refeições e ao maior IMC. Esses achados apontam a importância do consumo adequado desses alimentos que afetam diretamente o estado de saúde da população e que podem atuar na prevenção do desenvolvimento de doenças crônicas não transmissíveis, assunto esse de extrema relevância para os órgãos de saúde pública.

\section{Agradecimentos}

Agradeço ao CNPQ e ao Ministério da Saúde por financiar o projeto base da pesquisa e ao PIBIC pela bolsa de estudos.

${ }^{1}$ FILHO, Malaquias Batista; RISSIN, Anete. A transição nutricional no país: tendências regionais e temporais. Caderno Saúde Pública [online], Rio de Janeiro, v. 19, n. 1, p. $181-191$, jan. 2003.

${ }^{2}$ MARQUES, A. T. M. P. Nutrição no idoso: A problemática dos micronutrimentos. 2004. Monografia de conclusão de curso (Graduação em Nutrição) - Faculdade de Ciências da Nutrição e Alimentação, Universidade do Porto, Porto.

${ }^{3}$ GADENZ, Sabrina Dalbosco; BENVEGNU, Luiz antônio. Hábitos alimentares na prevenção de doenças cardiovasculares e fatores associados em idosos hipertensos. Ciênc. Saúde. Coletiva, Rio de Janeiro, v.18, n.12, p. 3523-3533, dez. 2013 